\title{
Multi-Direction Bridge Model Updating Using Static and Dynamic Measurement
}

\author{
Feng Xiao ${ }^{1}$, J. Leroy Hulsey ${ }^{1}$ \& Gang S Chen ${ }^{2}$ \\ ${ }^{1}$ Department of Civil Engineering, University of Alaska Fairbanks, Fairbanks, Alaska 99775, USA \\ ${ }^{2}$ College of IT \& Engineering, Marshall University, Huntington, WV 25755, USA \\ Correspondence: Feng Xiao, Department of Civil Engineering, University of Alaska Fairbanks, Fairbanks, \\ Alaska 99775, USA. E-mail: xfeng2@alaska.edu
}

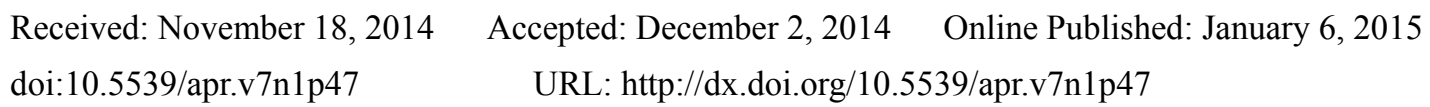

\begin{abstract}
This research present a multi-direction bridge finite element model updating method based on the static and dynamic test. A fiber optics structural health monitoring system was installed on the bridge site and 73 fiber optic sensors captured the static and dynamic data in local-level. A portable accelerometer system was used to record the ambient loading test and 15 force-balanced accelerometers were placed along bridge center to record the bridge global behavior. The original model was built according to the construction draw. The bridge model was updating by using multi-level test data. A new multi-direction model updating approach was established to separate the model updating into several stages based on the member's direction. In each stage, the uni-direction members were updating in local-global level. This study found the multi-direction model updating can reduce the number of objective functions and variables in each stage and bridge model updating in the uni-direction has limited influence on the other directions. It is necessary to update steel girder bridge's finite element model in the multi-direction in order to ensure the model's accuracy.
\end{abstract}

Keywords: bridge model updating, structural health monitoring, fiber optic

\section{Introduction}

Consider that the current approach to structural health monitoring can be divided into two distinct areas: (1) using the structural dynamic properties to detect structural behavior at the global level based on the dynamic parameters, and (2) using several sensors to quantify the condition of the local components of the bridge structure based on the static measurements. Both approaches have advantages and limitations. Dynamic parameters give information about the global response of structures and, therefore, are not very sensitive to local phenomena. On the other hand, static measurements, such as strains and displacements, are more sensitive to the response in their vicinity and, therefore, they better suited to determine local defects.

Model updating in global-local level will overcomes the week of only using one type of measurement and combined global-local performance will assist in evaluating the bridge behavior accurately, however, it will also enhance the number of objective functions which are the difference between the measurements and the analyzed results. In this case, more variables will be selected in order to make the objective functions coverage. A large number of objective function and variable will take longer time for mathematical operation. In order to solve this problem, a new bridge finite model updating strategy required to establish in order to control the number of functions and simplify the process of model updating.

This research effort is focused on developing an optimization technique for calibrating a finite element model against experimental data in local-global level. A new multi-direction model updating method have been developed in this paper. This approach will enable control the number of objective functions and simplified the process of model updating.

Compared with existing global-local bridge model updating, this approach used bridge members' direction to group bridge components. Girder, Stringer and Deck etc. are the longitudinal members and cross frame, roller support are the transversal members. Each direction members were updated in the global-local level independently. The advantage of this approach is it separates model updating into several stages and in each stage, the objective functions and variables are reduced. 
The study results indicated, updating uni-direction member can only enhance the accuracy in this direction and it have very low influence on the accuracy of other direction members. The overall accuracy of bridge model is contributed by both longitudinal members and transversal members.

\section{Bridge Description}

The Chulitna River Bridge was built in 1970 on a 22-degree skew. It is 790-feet long with five spans of 100, 185, 220, 185, and 100 feet (Figure 1). The superstructure was a 34-foot-wide by 63/4-inch-thick cast-in-place concrete deck supported by two exterior continuous longitudinal variable depth girders and three interior stringers. The girder stringers are spaced at 7 feet on center. The interior stringers are supported by cross frames that is carried by the exterior girders.

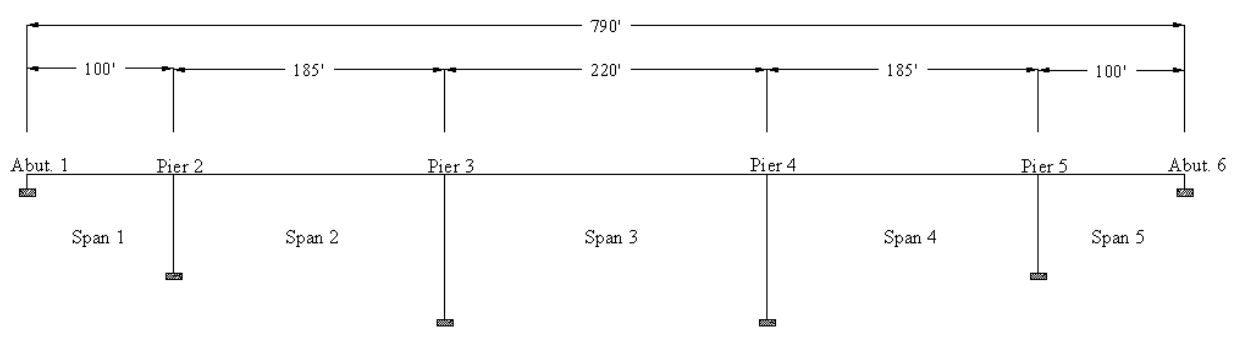

Elevation View

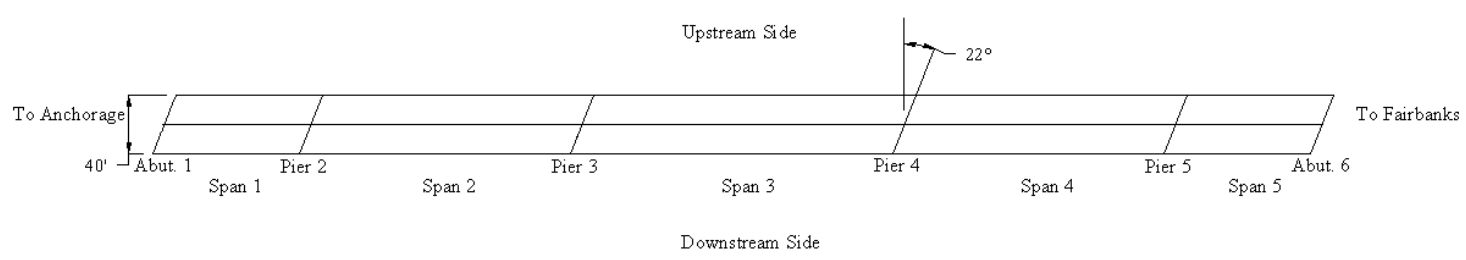

Plan View

Figure 1. Elevation and Plan View of Chultina River Bridge

In 1993, the bridge deck was widened and made of precast concrete deck panels. The increased load was accounted for by strengthening the variable depth exterior girders and converting the W21 444 interior stringers to an interior truss girder; the W21 444 stringer became the upper chord of the truss (Figure 2).

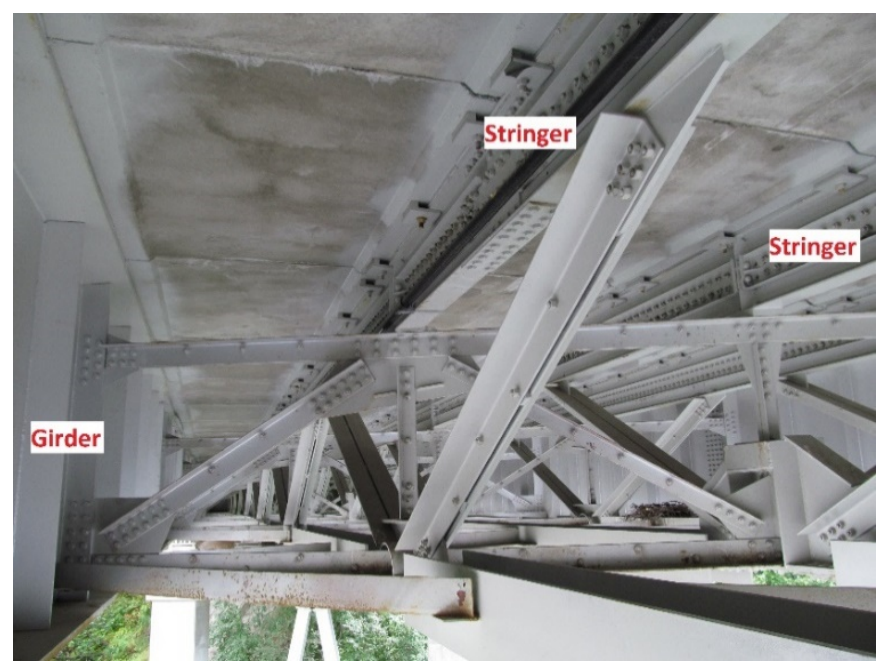

Figure 2. Current picture of the Chulitna River Bridge 


\section{Static and Dynamic Test}

The research team developed a structural health monitoring system (SHMS) that could be used to monitor Alaska bridges, instrument the bridge, calibrate the system, and load test the structure. In addition to monitoring the bridge response to traffic, the research team was to develop and calibrate a FEM that would provide a reliable bridge behavioral response to traffic AASHTO loading and special permitted vehicles. The paper provides the experimental data obtained from two different field-evaluation systems: local and global.

Localized response data are obtained through the use fiber-optic sensors such as strain gauges, displacement sensor, tilt meters, etc. at specific locations. In an attempt to understand and evaluate the response of the Chulitna River Bridge to traffic loads. The global field monitoring is an ambient acceleration study that attempts to identify natural frequencies of the structure once it is excited. Horizontal, vertical, and transverse frequencies were measured by 15 portable accelerometers distributed across the top deck of the structure.

There are various methods and sensors that may be used to evaluate the discrete locations (local-level monitoring) to evaluate long-term response of the structural elements. This may be accomplished by measuring at the discrete points, temperature, acceleration, strain, and deflection. Although there are various sensors available for measuring strains, etc., not all perform well over the long term. Thus, in this study, the researchers selected a Fiber-optic structural health monitoring system (Figure 3) for the purpose of insuring that drift would be minimized over time.

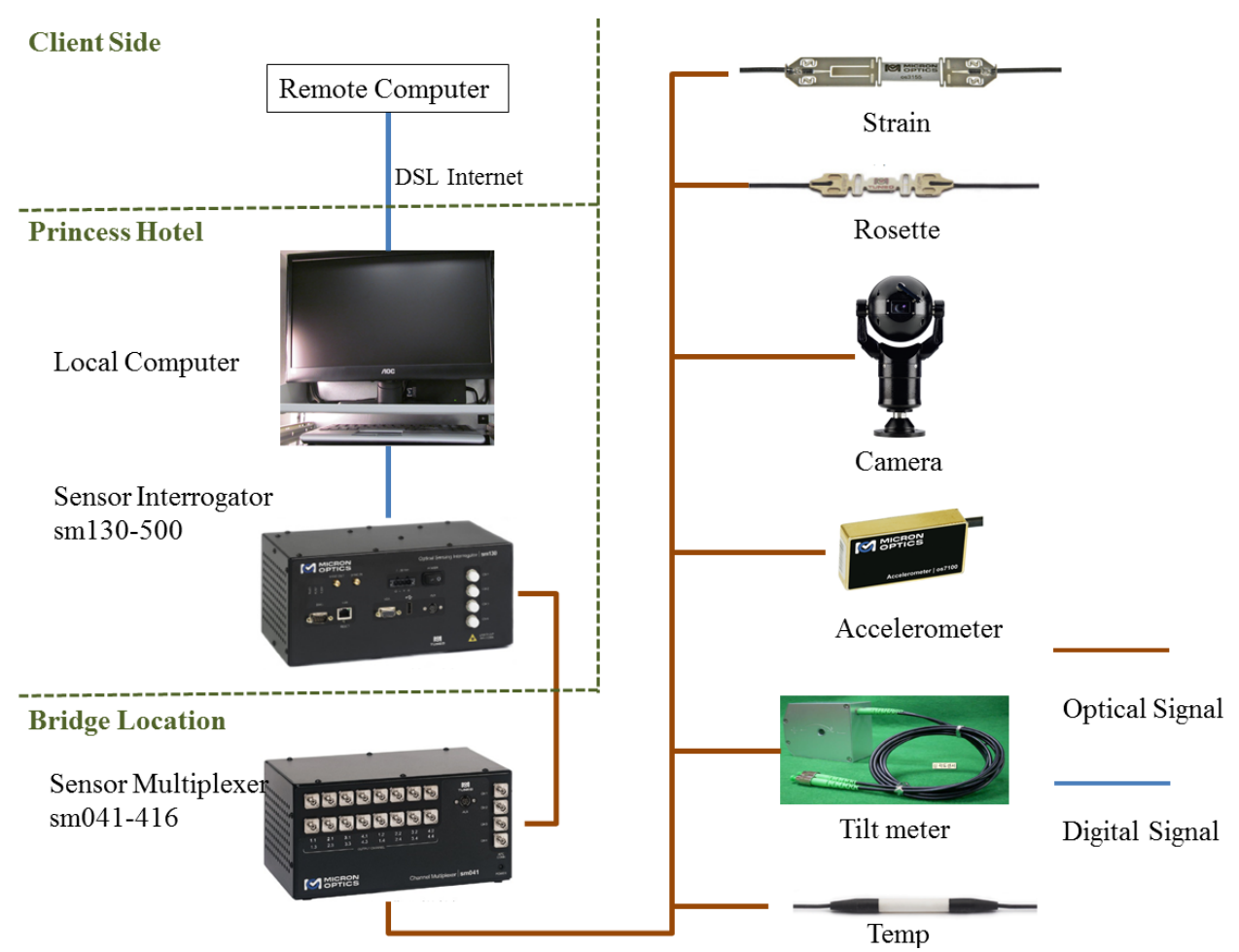

Figure 3. Fiber-Optic Structural Health Monitoring System

Fiber optic sensors have been shown to provide stable long-term real-time monitoring for bridge structures. In this research, the Chulitna River Bridge was instrumented to evaluate the local-level behavior. There are a total of 73 sensors (strain gages, accelerometers, temperature sensors, rosettes, and tilt meters) at locations that were selected to evaluate the local-level structural health of this structure. (Figure 4) The long-term monitoring can indicate the change of local components with time. 


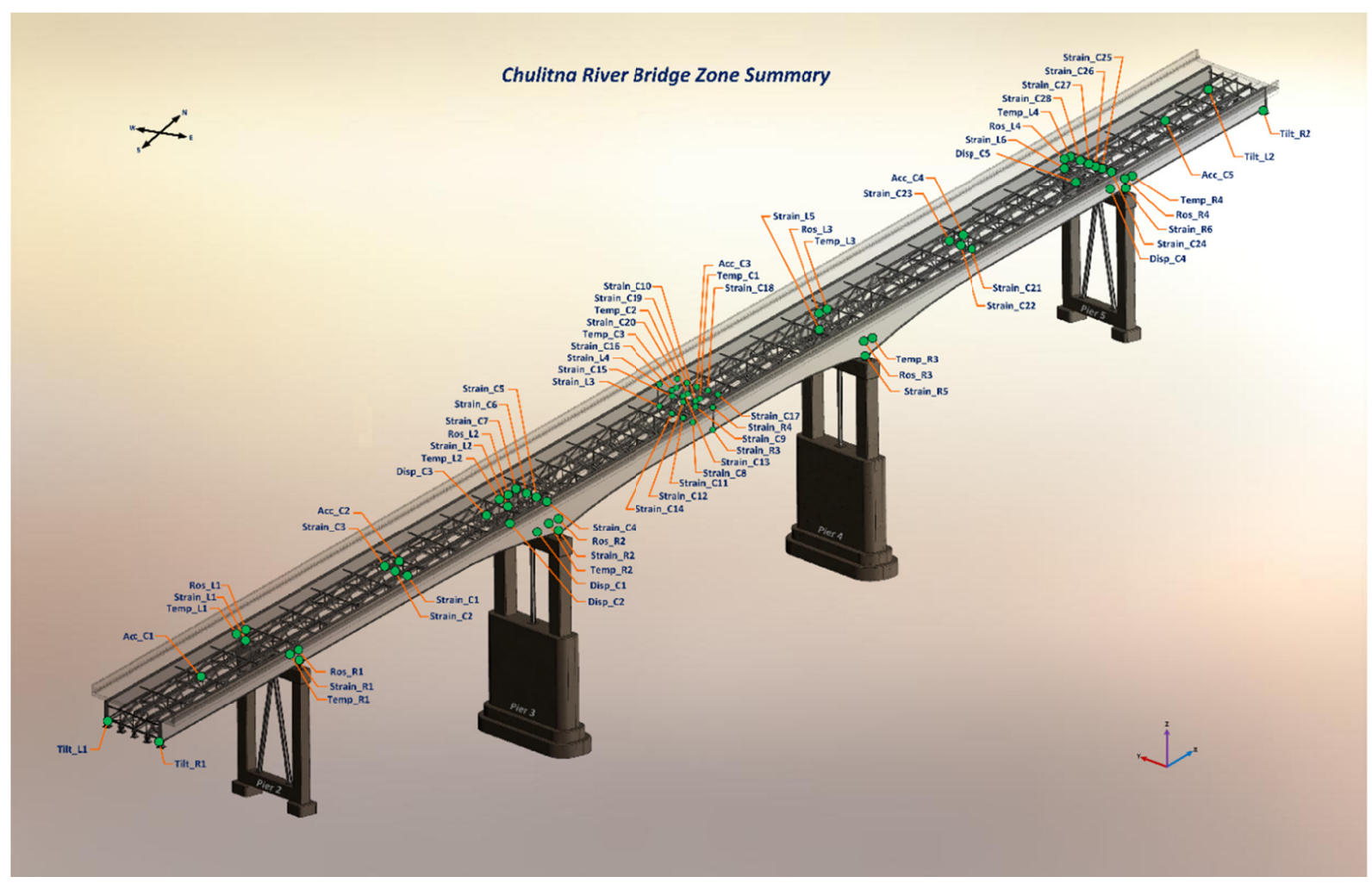

Figure 4. Bridge Health Monitoring System Sensor Summery

Consider a "Piezoelectric force" balanced portable data acquisition system, see Figure 5. It is a movable system that enables the engineer to record accelerations at several places along the bridge. The data is digital format in this study and it was used to identify dynamic behavior at the global-level. The recorded data was used to find natural frequencies, damping, mode shapes and identify possible nonlinear behavior. The resulting data is essential information for calibrating and updating the global-level performance of a virtual model of the bridge. In this study, the researcher was calibrated the virtual model using finite elements to approximate behavior of the structure.

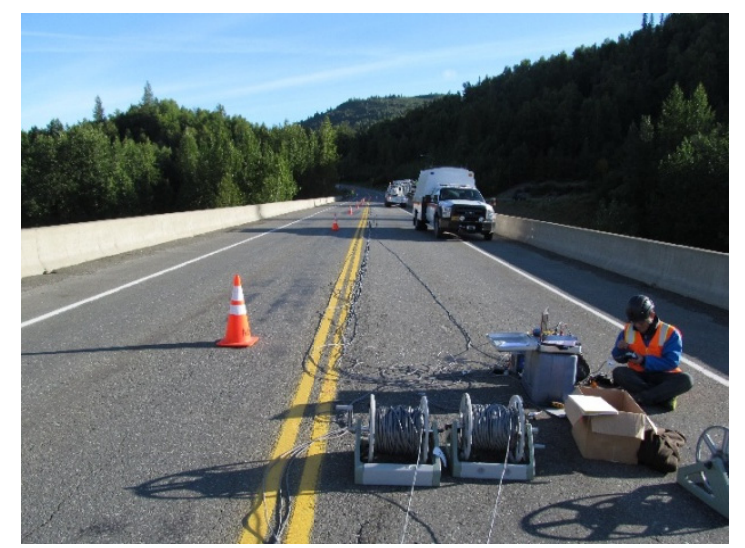

Figure 5. Using Portable Data Acquisition System on the Chulitna River Bridge

Earlier research by the author has shown that the errors between natural frequencies' evaluated from field measurements versus those calculated using an initial finite element model of this bridge is up to $10 \%$ (Table 1). These results are a global-level comparison. However, a comparison between strain values evaluated using the field measured strains (using fiber optic sensors) and the initial finite element values at mid-span were in error by as much as $150 \%$. 


\section{Multi-Direction Model Updating}

In this research, an enhanced approach for updating the virtual bridge model was developed. The idea is that this model will represent the structural response when subjected to load conditions typically expected in the field. The virtual model (FEM) for this bridge will be calibrated to reduce errors in global-local evaluation so that the virtual model may more accurately be calibrated and updated and it accurately represents the behavior and condition of the structure. Combined the global and the local evaluation, it will introduce more variables to be adjusted and it will involve more objective functions to be solved. It is a challenge to make the objective functions coverage when there are a large number of variables. This section shows the multi-direction global-local model updating approach which can solve this problem and simply the model calibration for large complicated bridge structure.

\subsection{Simple Accuracy Test}

Before model changes were made, simple accuracy tests were performed on the bridge initial finite element model. That is, the number of elements (original mesh) was increased in an effort to evaluate the results for a newly refined mesh. This test was conducted to ensure that it would converge to provide a reasonable estimate of the structural response. The desired level of accuracy was set at $2 \%$. Subsequently, the mesh size was reduced to half its current size to determine if the resulting displacements and forces would change significantly or if the change was small enough to be considered acceptable. Multiple locations on the bridge were checked. These locations were ones of critical interest to the project (i.e., high tension, large displacement, etc.). Nine sections were considered when checking the strains and stresses. These nine sections are located in different spans and sides of the bridge. Four longitudinal displacements on different sides of the abutments were selected for checking. We refined the mesh for the FEM to half its current size in both lines and areas. In Table 1, the error shows the difference between the initial model and the refined model. This comparison is based on three trucks that were stopped and positioned so that the front axles were 369 feet from the south abutment (Abutment 1); the three trucks were in the middle of Span 3.

The locations that are presented in Table 1 are illustrated in Figure 6. Table 1 indicates that the error between the two models is low. Ignoring the sign, the largest error is $1.04 \%$, which is within the acceptable the level of accuracy. In general, the fine mesh used in the initial model should give sufficiently accurate results.

Table 1. Simple Accuracy Comparison between the Initial model and the refined model

\begin{tabular}{|c|c|c|c|c|c|c|}
\hline & \multicolumn{2}{|l|}{ Locations } & Number & $\begin{array}{l}\text { Initial } \\
\text { Model }\end{array}$ & $\begin{array}{c}\text { Refined } \\
\text { Model }\end{array}$ & $\begin{array}{l}\text { Error } \\
(\%)\end{array}$ \\
\hline \multirow{9}{*}{ Force (lbs) } & \multirow{3}{*}{ Mid-Span 2 Lower Chord } & East & 1 & $-25,388$ & $-25,476$ & -0.35 \\
\hline & & Middle & 2 & $-25,739$ & $-25,858$ & -0.46 \\
\hline & & West & 3 & $-26,612$ & $-26,673$ & -0.23 \\
\hline & \multirow{3}{*}{ Mid-Span 3 Lower Chord } & East & 4 & 80,867 & 81,199 & -0.41 \\
\hline & & Middle & 5 & 83,554 & 83,893 & -0.41 \\
\hline & & West & 6 & 81,238 & 81,584 & -0.43 \\
\hline & \multirow{3}{*}{ Mid-Span 4 Lower Chord } & East & 7 & $-26,447$ & $-26,562$ & -0.43 \\
\hline & & Middle & 8 & $-25,474$ & $-25,624$ & -0.59 \\
\hline & & West & 9 & $-25,546$ & $-25,625$ & -0.31 \\
\hline \multirow{4}{*}{$\begin{array}{l}\text { Displacement } \\
\text { Long. Dir. (mm) }\end{array}$} & \multirow{2}{*}{ Abutment 1 Roller Support } & East & 10 & -2.81 & -2.84 & -1.04 \\
\hline & & West & 11 & -2.82 & -2.84 & -0.66 \\
\hline & \multirow{2}{*}{ Abutment 2 Roller Support } & East & 12 & -2.21 & -2.23 & -0.92 \\
\hline & & West & 13 & -2.21 & -2.21 & -0.12 \\
\hline
\end{tabular}




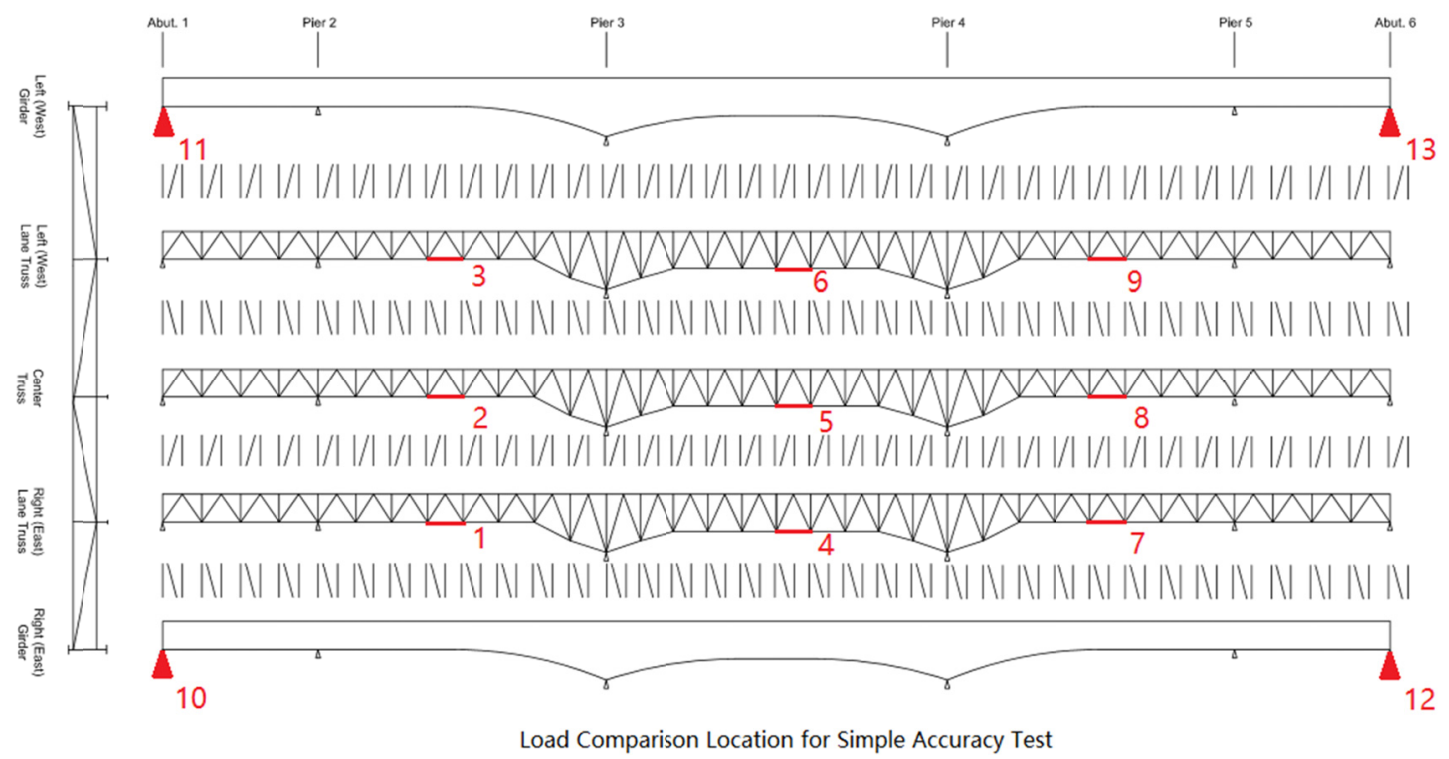

Figure 6. Locations where the Influence of Mesh Refinement was checked (see Table 1)

At this point, the results of this test simply prove that if this model represents the actual bridge structure, the model will provide sufficiently accurate strains, displacements, and forces for a given set of loads. The results of this test do not prove that the model represents the bridge structure that is being studied.

\subsection{Group Directional Members and Select Objective Functions}

The model updating was divided into two stages based on the longitudinal and the transversal directions. Girder, stringer and concrete deck belong to longitudinal member. The longitudinal objection function $\left(\mathrm{J}_{1}\right)$ is the difference between experimental data $\left(\mathrm{Z}_{\mathrm{e} 1}\right)$ and model analysis $\left(\mathrm{Z}_{\mathrm{m} 1}\right)$ in local-level longitudinal member and global-level natural frequencies. The number of selected variable is $n_{1}$.

$$
J_{1}=\sum_{i=1}^{n_{1}} \sqrt{\frac{\left(Z_{e 1}-Z_{m 1}\right)^{2}}{Z_{e 1}{ }^{2}}}
$$

The cross frames and roller supports are the transversal members. The objection function $\left(\mathrm{J}_{2}\right)$ is the difference between experimental data $\left(\mathrm{Z}_{\mathrm{e} 2}\right)$ and model analysis $\left(\mathrm{Z}_{\mathrm{m} 2}\right)$ in local-level transversal member and global-level natural frequencies. The number of variable is $n_{2}$.

$$
J_{2}=\sum_{i=1}^{n_{2}} \sqrt{\frac{\left(Z_{e 2}-Z_{m 2}\right)^{2}}{Z_{e 2}{ }^{2}}}
$$

In each model development stage, the direction members are changed in a reasonable range to make the objective functions converge. In order to show the overall behavior of model updating, the objective function $(\mathrm{J})$ is the error between experimental data $\left(Z_{\mathrm{e}}\right)$ and model analysis $\left(Z_{\mathrm{m}}\right)$ in both longitudinal, transversal member and global natural frequencies. The number of variable is $n$ which is the sum of $n_{1}$ and $n_{2}$.

$$
\mathrm{J}=\sum_{i=1}^{n} \sqrt{\frac{\left(Z_{e}-Z_{m}\right)^{2}}{Z_{e}^{2}}}
$$

\subsection{Bridge Longitudinal Direction Behavior}

Thirteen fiber-optic strain sensors were installed in the middle of Span 3 longitudinal members including stringers and girder's flanges and lower chords (Figure 7). The strains in these sensors were used to evaluate the influence of the three ADOT\&PF trucks driving side by side. Figures 8 show a comparison between stresses obtained from measured strain data and the "before modification" original FEM calculated mid-span stresses. The results indicate that the FEM-calculated stresses carried by the composite trusses are higher than measured; 
that is, calculated lower chord stresses are higher than measured. This finding illustrates that the FEM does not properly represent the distribution of stiffness between the bridge composite stringers and the girders. In consideration of these problems, objective functions $\mathrm{J}_{1}$ in longitudinal members were selected for study. Modifications to the objective functions affected load distribution for the composite trusses and girders.

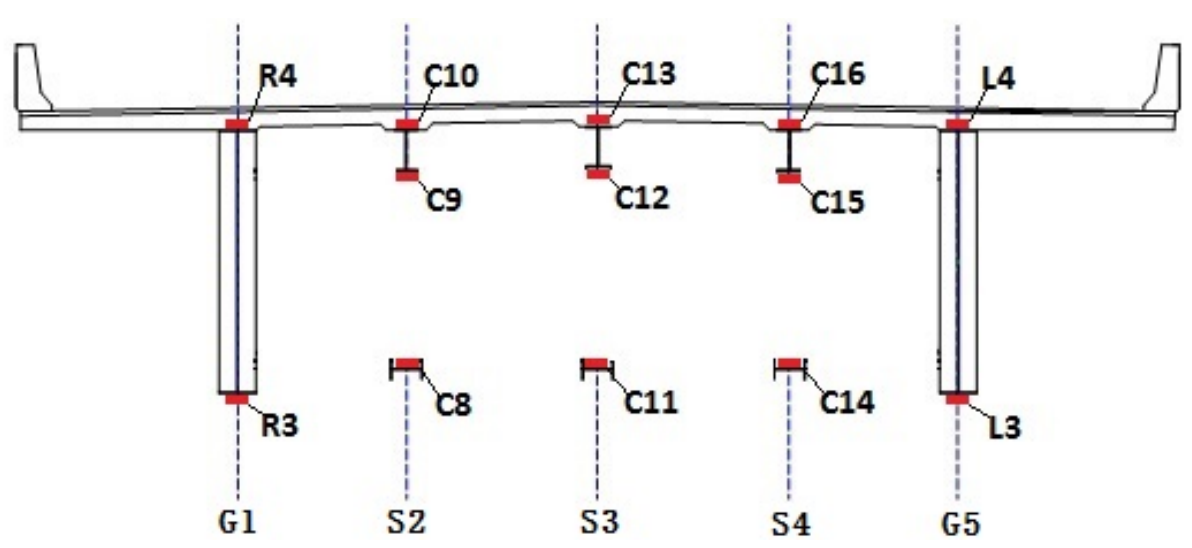

Figure 7. Strain Sensor at the cross section of Mid-span 3

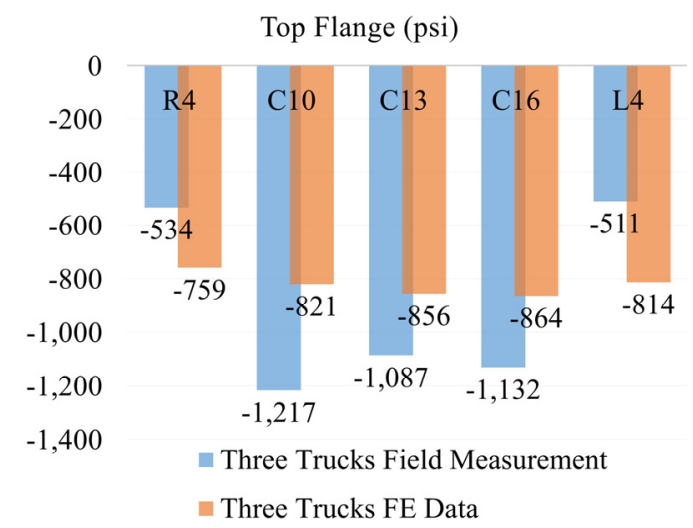

a. Top flange stress comparison between field measured and calculated values (psi)

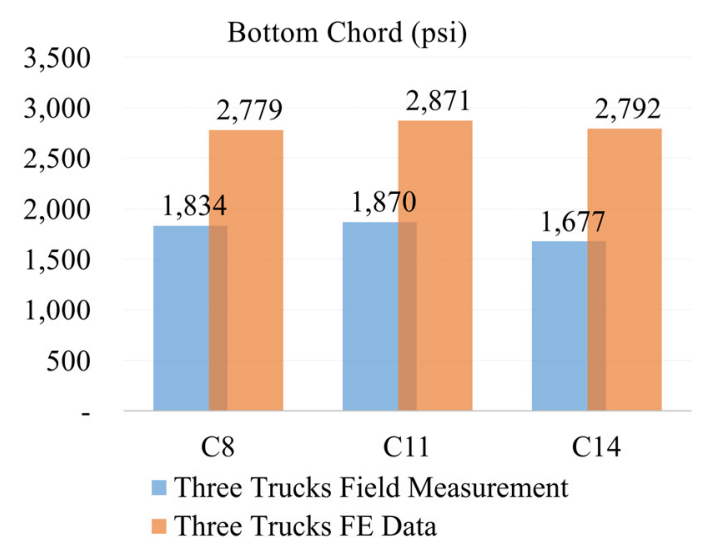

c. Lower chord stress comparison between measured and calculated values (psi)

Figure 8. Stress Compression in Longitudinal Members before Modification

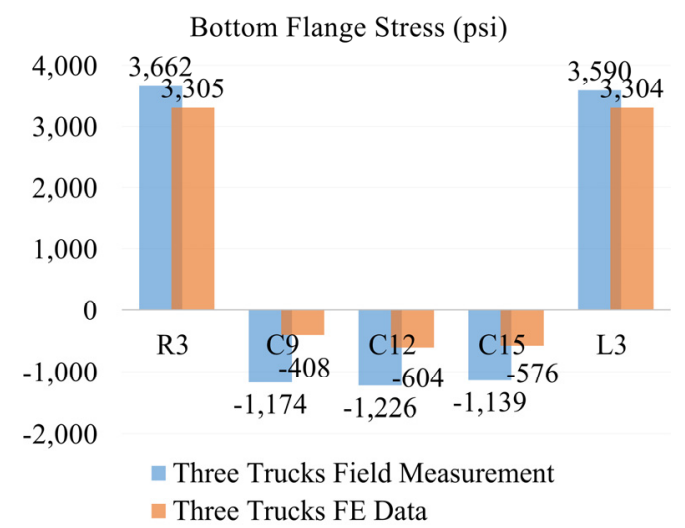

b. Bottom flange stress comparison between measured and calculated values (psi) 


\subsection{Model Updating in Longitudinal Direction}

Initially, we identified the members that were likely to affect structural response the most. In selecting objective functions for study, we adjusted member sectional data and member geometry to better reflect the 1993 as-is bridge condition. According to the longitudinal behavior described by the initial FEM, the largest error exists in a lower chord member. Modifications showed that if the cross-sectional area in the lower chord was reduced to 0.43 , the resulting error in local strain dropped below $50 \%$. This modification resulted in a change in behavior, and the largest error between measured and calculated stresses was now in the composite truss lower flange. We then investigated the bridge response to a change in stiffness for the concrete deck. Changing the elastic modulus of the concrete deck to 3,000 ksi improved structural response, and the error between the calculated and measured stresses were reduced to $5 \%$. However, the difference between the global experimental frequency response and calculated values causes the percent error to increase to $15 \%$. The stiffness change went from too stiff to too flexible. In order to balance the difference in error between local and global values, the elastic modulus of the concrete deck was changed to 3,300 ksi and the stringer lower flange area was changed from 2.0 to 2.5. The change in area represents the as-is bridge condition. Table 2 shows the influence of these modifications on structural response. Tables 3, 4, and 5 show the longitudinal difference between experimental and calculated stresses for both global and local values.

Ignoring signs, the largest error for the global values decreased from $10.2 \%$ to $8.8 \%$, and the largest error for the local values decreased from $66.4 \%$ to $17.8 \%$ in longitudinal direction.

Table 2. FEM using revised variables

\begin{tabular}{llll}
\hline Bridge Sections & Locations & \multicolumn{2}{c}{ Property Modifiers } \\
\hline Composite Trusses & 3 Lower Chord & Area & 0.43 \\
Girders & 2 Top Flange & Area & 0.54 \\
& 2 Bottom Flange & Area & 0.85 \\
\multirow{2}{*}{ Stringer } & 3 Top Flange & Area & 1.24 \\
& 2 Bottom Flange (No. 2,4) & Area & 2.0 \\
Concrete Deck & Bottom Flange (No. 3) & Area & 2.5 \\
& Throughout the deck & Elastic Modulus (ksi) & 3,300 \\
\hline
\end{tabular}

Table 3. Natural frequency differences after model revisions for longitudinal behavior

\begin{tabular}{llll}
\hline Mode & Field Measurement $(\mathrm{Hz})$ & Long. Updated FEM $(\mathrm{Hz})$ & Difference $(\%)$ \\
\hline Longitudinal Mode 1 & 1.500 & 1.368 & 8.8 \\
Longitudinal Mode 2 & 2.190 & 2.036 & 7.0 \\
Vertical Mode 1 & 2.846 & 2.773 & 2.6 \\
Vertical Mode 2 & 3.224 & 3.196 & 0.9 \\
Vertical Mode 3 & 4.580 & 4.271 & 6.8 \\
Transverse Mode 1 & 2.095 & 2.168 & -3.5 \\
Transverse Mode 2 & 2.346 & 2.325 & 0.9 \\
Transverse Mode 3 & 2.782 & 2.683 & 3.6 \\
\hline
\end{tabular}

Table 4. Difference in flange stress (\%) after model revisions for longitudinal behavior

\begin{tabular}{|c|c|c|c|c|c|c|}
\hline \multicolumn{2}{|c|}{ Location } & G1 & $\mathrm{S} 2$ & S3 & S4 & G5 \\
\hline \multicolumn{2}{|c|}{ Sensor Number } & R4 & C9 & $\mathrm{C} 12$ & $\mathrm{C} 15$ & L4 \\
\hline Top Flange & $\begin{array}{c}\text { Field Measurement } \\
\text { FE Data }\end{array}$ & -12.4 & -12.0 & -17.8 & -17.4 & -12.0 \\
\hline \multicolumn{2}{|c|}{ Sensor Number } & R3 & $\mathrm{C} 8$ & $\mathrm{C} 11$ & $\mathrm{C} 14$ & L3 \\
\hline Bottom Flange & $\begin{array}{c}\text { Field Measurement } \\
\text { FE Data }\end{array}$ & -6.7 & 1.2 & 11.7 & 5.7 & -9.9 \\
\hline
\end{tabular}


Table 5. Difference in lower chord stress (\%) after model revisions for longitudinal behavior

\begin{tabular}{|c|c|c|c|c|}
\hline \multicolumn{2}{|c|}{ Location } & $\mathrm{S} 2$ & $\mathrm{~S} 3$ & $\mathrm{~S} 4$ \\
\hline \multicolumn{2}{|c|}{ Sensor Number } & $\mathrm{C} 8$ & C11 & $\mathrm{C} 14$ \\
\hline Lower Chord & $\begin{array}{c}\text { Field Measurement } \\
\text { FE Data }\end{array}$ & -3.8 & -6.8 & -14.0 \\
\hline
\end{tabular}

\subsection{Bridge Transversal Direction Behavior}

The stiffness of the cross frame and the condition of the supports determined load distribution in the transversal direction. In the investigation by HDR, Inc., five roller bearings did not fully connect with the superstructure (Figure 9), and original model removed those supports.

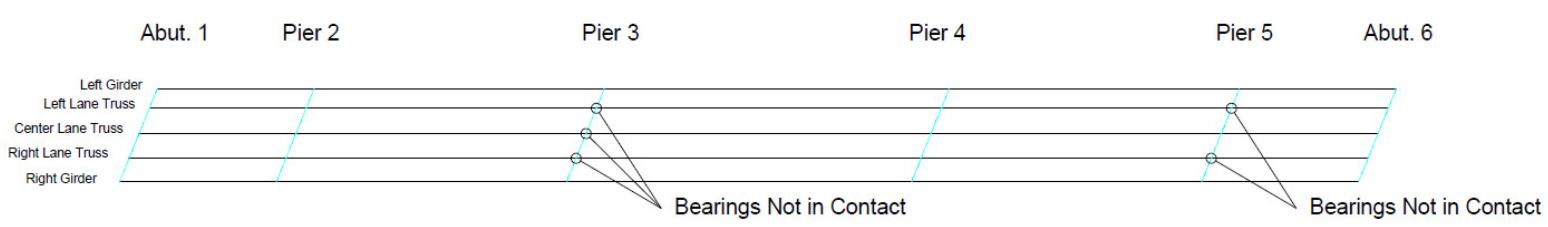

Figure 9. Plan view: Bearings that are not contact with masonry plates

In Fiber Optic SHMS, there are five displacement sensors are placed at those locations to measure the movement of the roller bearings in the vertical direction. In addition, we installed eight strain sensors in diagonal members in cross section of pier 3 (Figure 10) and pier 5 (Figure 11) to measure the reaction of the supports and the stresses in the cross frames.

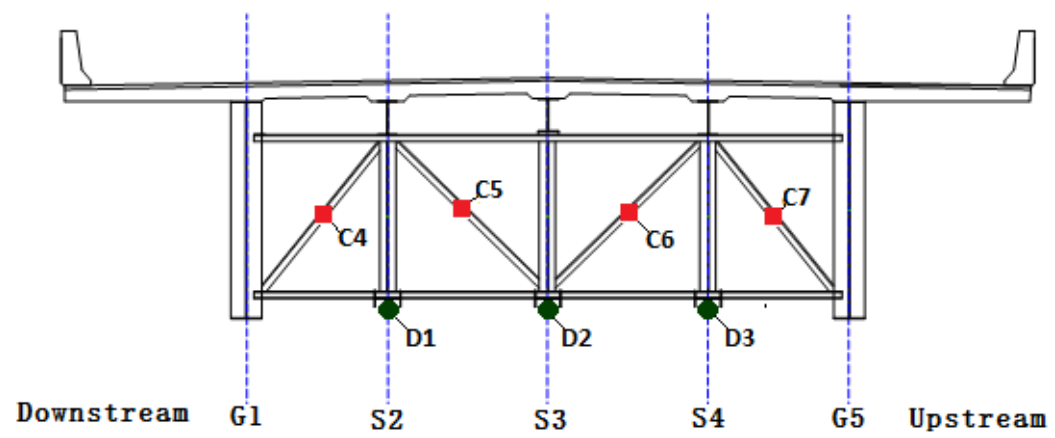

Figure 10. Strain Sensor (Red) and Displacement Sensor (Green) at the Cross Section of Pier 3

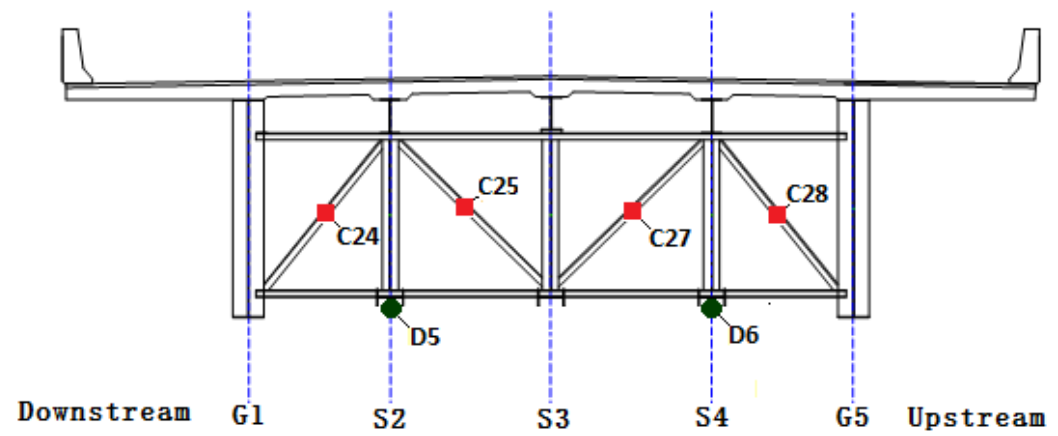

Figure 11. Strain Sensor (Red) and Displacement Sensor (Green) at the Cross Section of Pier 5

The load test cases conducted on September 10, 2012, three heavily loaded trucks traveling side by side crossed the bridge at low speed. The vertical movement of the five displacement sensors is shown in Figure 12 a-e. These graphs illustrate the response for an average of 50 data points over time for each of the five bearing locations. 


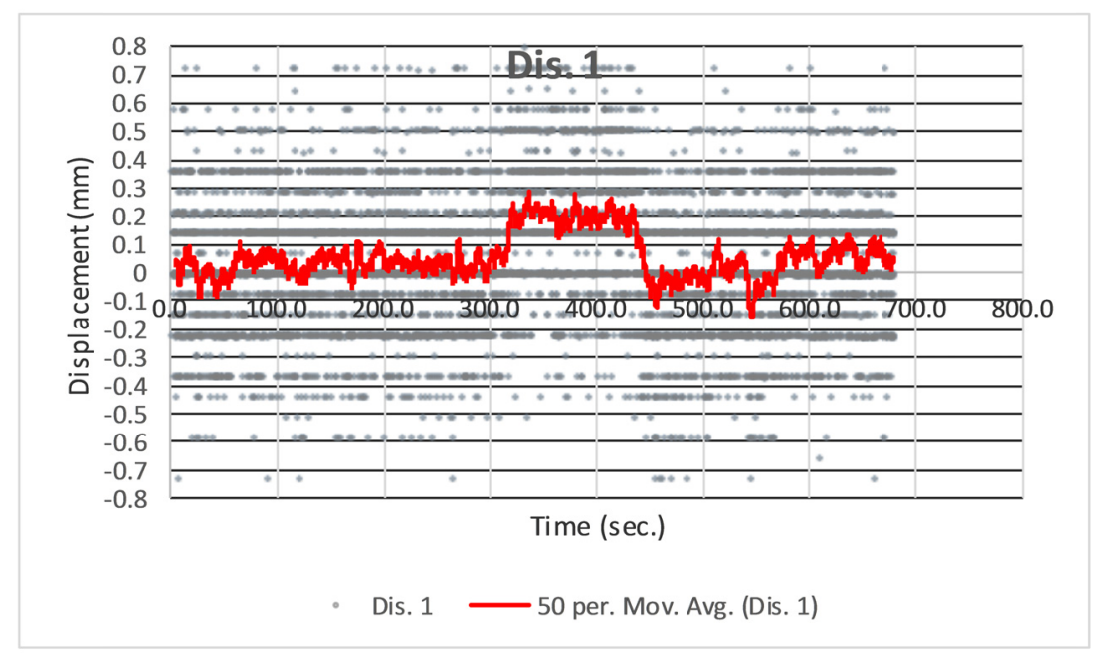

a. Vertical movement at displacement sensor 1

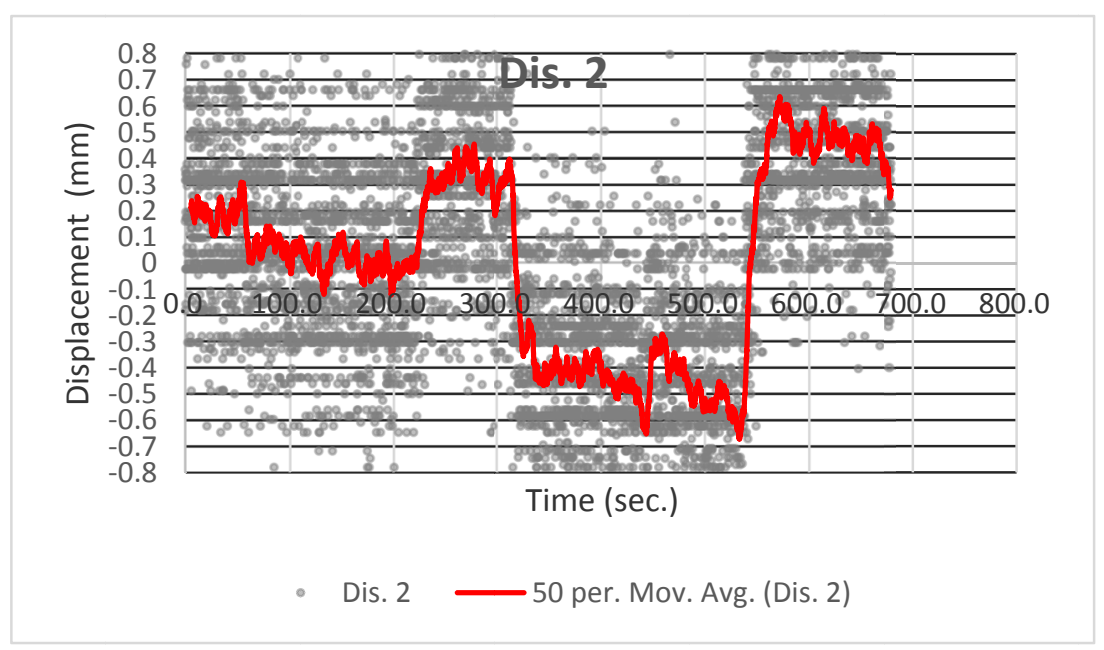

b. Vertical movement at displacement sensor 2

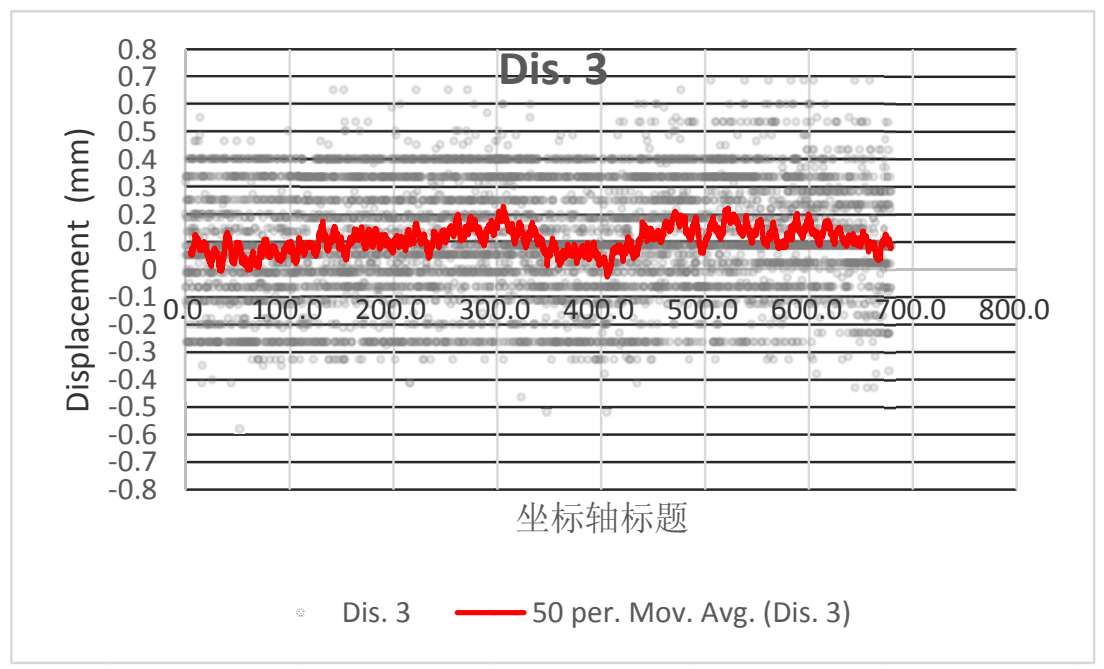

c. Vertical movement at displacement sensor 3 


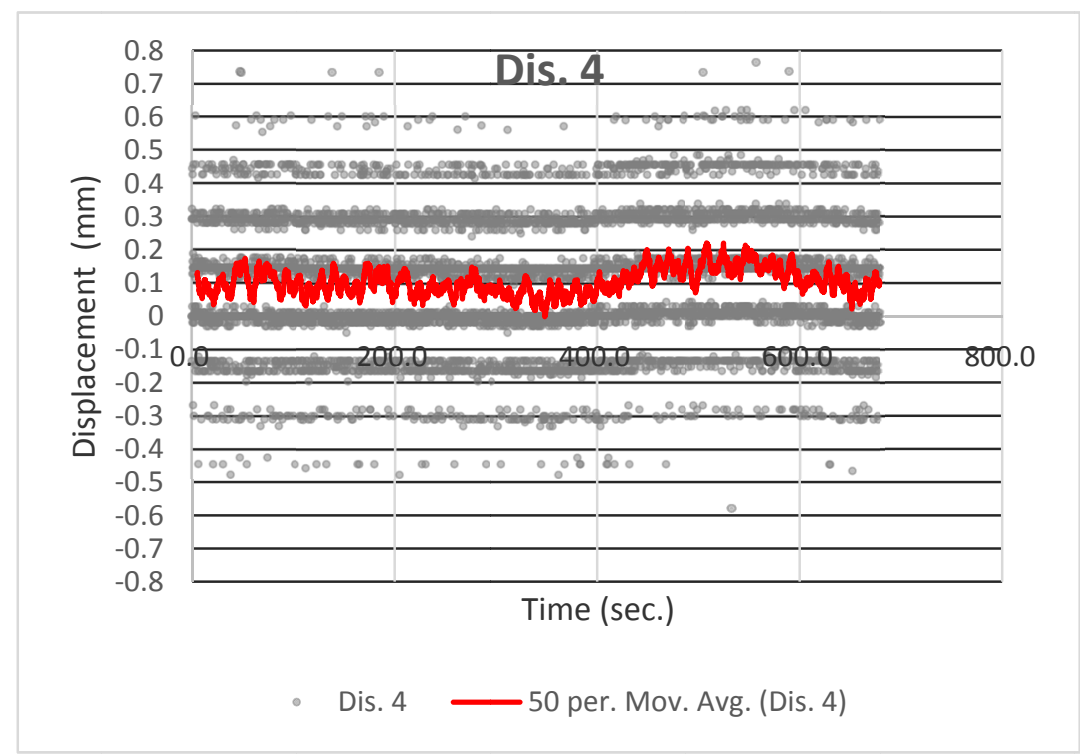

d. Vertical movement at displacement sensor 4

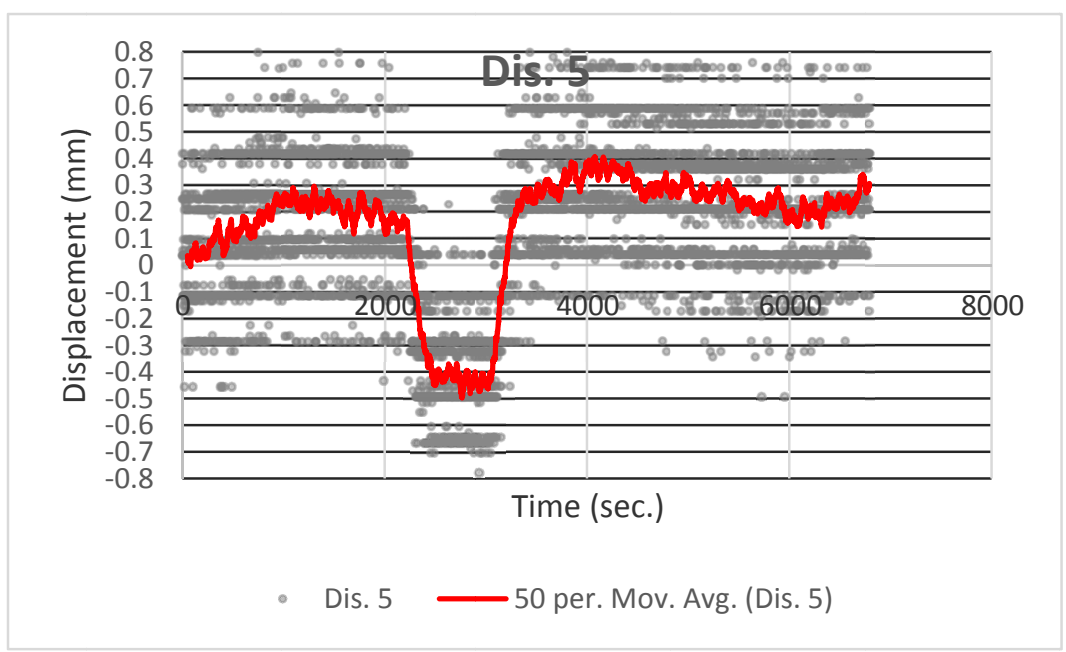

e. Vertical movement at displacement sensor 5

Figure 12. Vertical movement at 5 unconnected bearing supports

According to the displacement sensor results, roller bearings 1,3, and 4 have limited movement in the vertical direction. When compared with the other roller bearings, bearings 2 and 5 are more flexible in the vertical direction than the others are.

In order to evaluate the distribution of reaction forces for a given load, eight strain sensors were installed on the cross frame at the five unconnected roller support locations (Figure 10,11). Tables 6 and 7 and Figures 13 show the stress results of measured and FEM stress before the model was updated. Table 6 and Figure 13 (a) shows the stress results when two parallel trucks stop above Pier 3. Table 7 and Figure 13 (b) shows stress results when two parallel trucks stop over Pier 5.

Table 6. Two trucks at Pier 3, before transverse modifications

\begin{tabular}{ccccc}
\hline Location & C7 & C6 & C5 & C4 \\
\hline Measured Stress (psi) & $-2,237$ & 1,127 & 1,726 & $-2,021$ \\
HDR FEM Stress (psi) & $-2,963$ & 1,482 & 1,466 & $-2,898$ \\
Error (\%) & -32.4 & -31.5 & 15.1 & -43.4 \\
\hline
\end{tabular}


Table 7. Two trucks at Pier 5 stress results before transverse updating

\begin{tabular}{ccccc}
\hline Location & $\mathrm{C} 28$ & $\mathrm{C} 27$ & $\mathrm{C} 25$ & $\mathrm{C} 24$ \\
\hline Measured Stress (psi) & $-2,171$ & $-2,058$ & -376 & $-1,172$ \\
HDR FEM Stress (psi) & $-2,184$ & $-2,366$ & $-2,305$ & $-2,261$ \\
Error (\%) & -0.6 & -15.0 & -512.3 & -92.9 \\
\hline
\end{tabular}

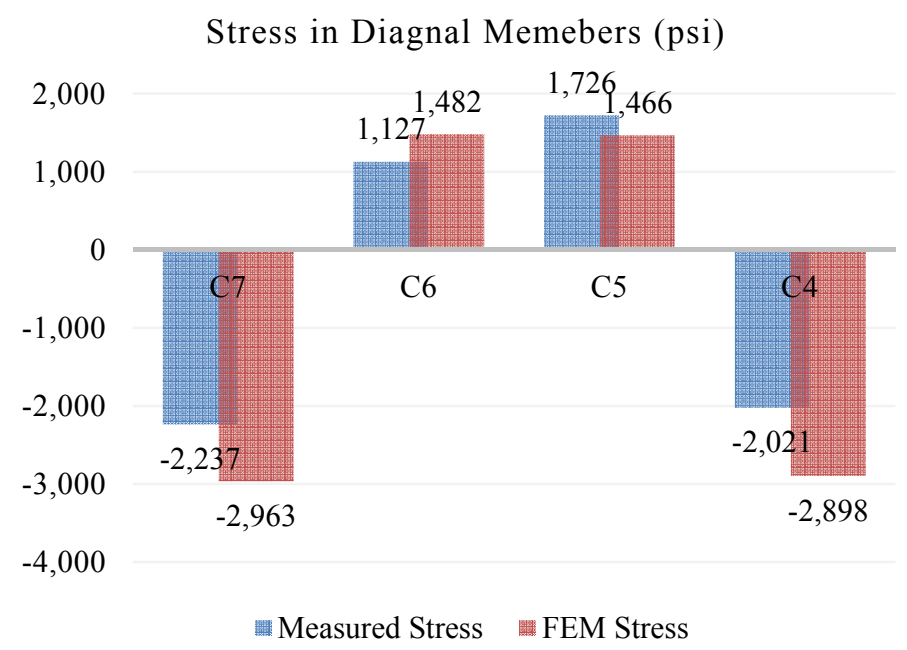

a. Two trucks at Pier 3 stress results before FEM transverse modifications

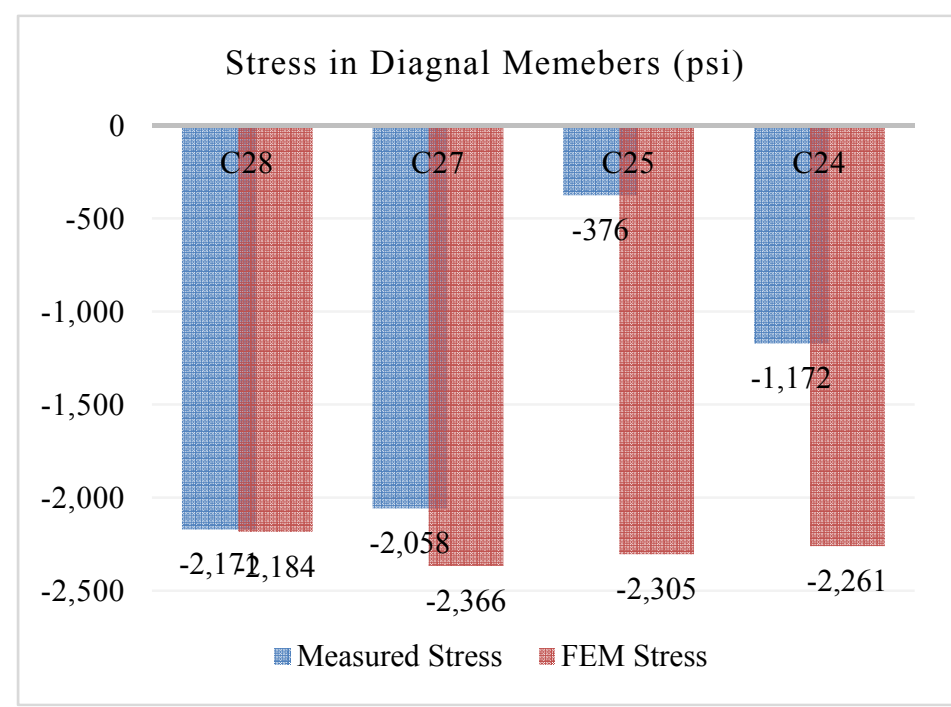

b. Two trucks at Pier 5 stress results before transverse updating

Figure 13. Stress Comparison in Cross-Frames before Model updating in Transversal Direction

\subsection{Model Updating in Transversal Direction}

Figures 13 shows for the 2012 load tests that large errors exist between measured and calculated stresses in the cross frame. At Pier 3, the largest error is $-43.4 \%$ in the cross frame. At Pier 5, the largest error was $-512.3 \%$. Figure 12 indicates that bearings 1,3 , and 4 have limited movement. So the cross frame section may work as a semi-rigid support at those locations. As part of the model modifications, three spring supports were added at those locations. In order to reduce errors in the objective functions, we modified the support spring stiffness and sectional properties of the cross frame to more closely represent bridge as-is condition. Vertical spring support stiffness at 
locations 1,3 and 4 are 1,200 kip/inch, $100 \mathrm{kip} / \mathrm{inch}$, and 40,000 kip/inch, respectively. The cross frame truss section area was decreased to 0.8. The results for the modified FEM are shown in Tables 8 and 9 and Figures 14 .

Table 8. Two trucks at Pier 3 stress results after model modificatons (psi)

\begin{tabular}{ccccc}
\hline & $\mathrm{C} 7$ & $\mathrm{C} 6$ & $\mathrm{C} 5$ & $\mathrm{C} 4$ \\
\hline Measured Stress (psi) & $-2,237$ & 1,127 & 1,726 & $-2,021$ \\
FEM Stress (psi) & $-2,419$ & 1,002 & 1,560 & $-2,106$ \\
Error (\%) & -8.1 & 11.1 & 9.6 & -4.2 \\
\hline
\end{tabular}

Table 9. Two trucks at Pier 5 stress results after model modifications (psi)

\begin{tabular}{ccccc}
\hline & $\mathrm{C} 28$ & $\mathrm{C} 27$ & $\mathrm{C} 25$ & $\mathrm{C} 24$ \\
\hline Measured Stress (psi) & $-2,171$ & $-2,058$ & -376 & $-1,172$ \\
FEM Stress (psi) & $-1,8301$ & $-1,0813$ & $-2,027$ & -946 \\
Error (\%) & 11.3 & -17.0 & -19.9 & 19.3 \\
\hline
\end{tabular}

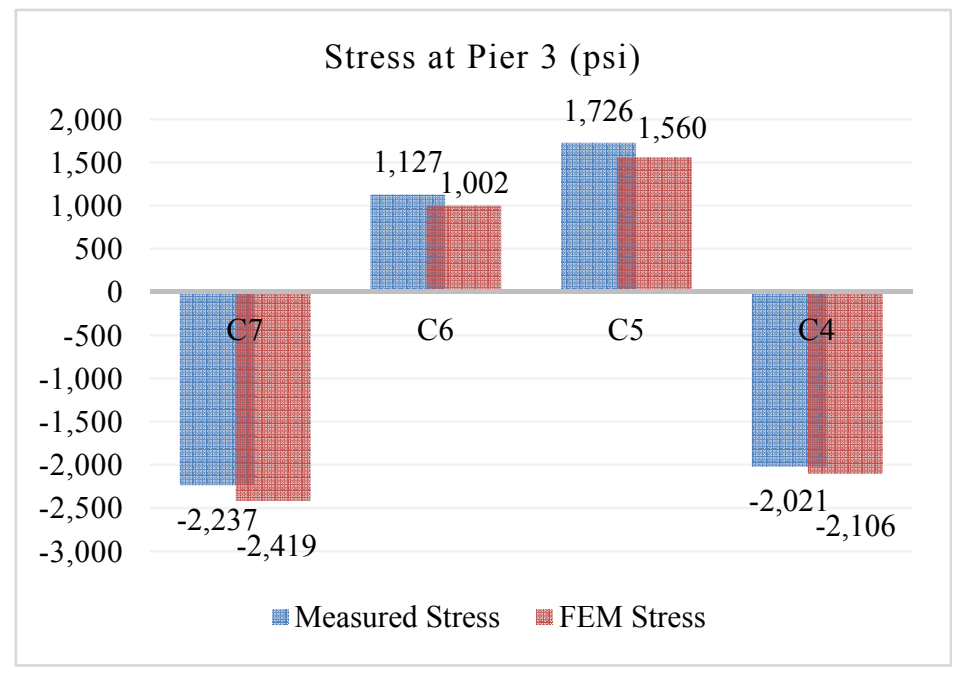

a: Two trucks at Pier 3 stress results after model modifications

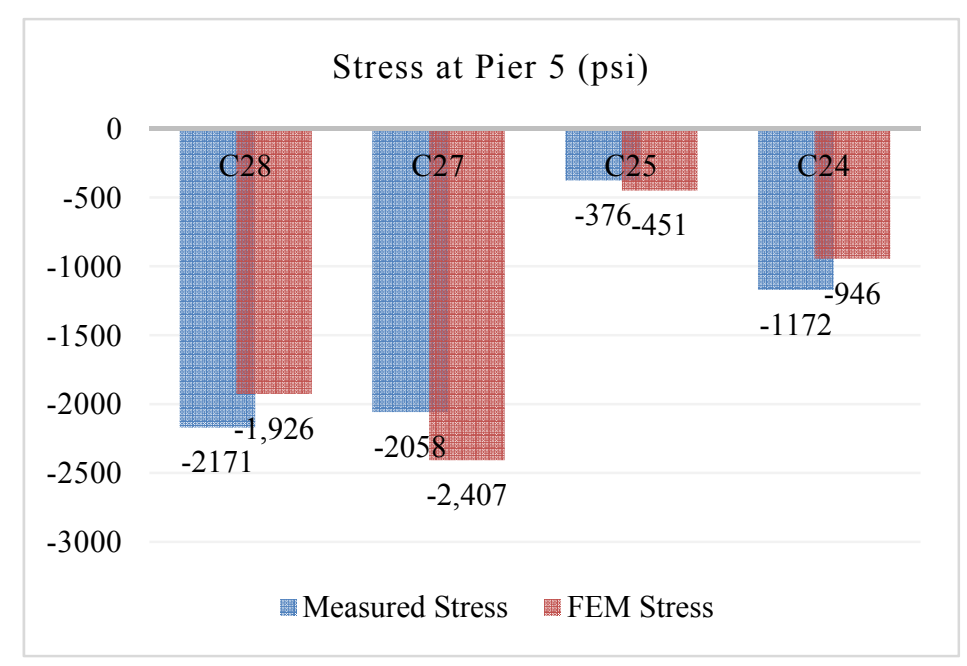

b. Two trucks at Pier 5 stress results after model modifications

Figure 14. Stress Comparison in Cross-Frames after Model updating in Transversal Direction 
Following modification of the model, the largest error in the transversal direction decreased from $-512.3 \%$ to $-19.9 \%$. Initially, five support bearings did not support the bridge (i.e., the superstructure was not in contact with the bearings). After the model was modified, we simulated the bridge response with two bearings (Bearings 2 and 4) that were not in contact with the structure. At the other three bearing locations, the superstructure is modeled with vertical springs between the bearing support and the structure. The cross frames were found to be too stiff compared with the bridge as-is condition.

After the FEM was modified to more accurately represent the transverse behavior of the bridge, a comparison between experimental and calculated stresses were made for the various load tests that were run on September 10 , 2012. For example, Tables 10 and 11 show the difference in stresses between experimental and modified finite element values for the middle of the Span 3 girder flanges and the difference in stresses in the lower chord of the cross frame. These stresses are from a static load test in which three trucks side-by-side were on the bridge mid-span 3 (see Figure 15). The tables 10 and 11 show that the stiffness of the three spring supports and the cross frame had limited influence on the longitudinal distribution of load.

Table 10. Percent difference between FEM and experimental flange stresses mid-Span 3

\begin{tabular}{|c|c|c|c|c|c|c|}
\hline \multicolumn{2}{|c|}{ Location } & G1 & $\mathrm{S} 2$ & S3 & $\mathrm{S} 4$ & G5 \\
\hline \multicolumn{2}{|c|}{ Sensor Number } & $\mathrm{R} 4$ & C9 & $\mathrm{C} 12$ & $\mathrm{C} 15$ & $\mathrm{~L} 4$ \\
\hline Top Flange & $\begin{array}{c}\text { Field Measurement } \\
\text { FE Data }\end{array}$ & -13.10 & -13.50 & -16.48 & -17.69 & -9.19 \\
\hline \multicolumn{2}{|c|}{ Sensor Number } & $\mathrm{R} 3$ & $\mathrm{C} 8$ & $\mathrm{C} 11$ & $\mathrm{C} 14$ & L3 \\
\hline Bottom Flange & $\begin{array}{c}\text { Field Measurement } \\
\text { FE Data }\end{array}$ & -6.58 & 0.71 & 5.43 & 4.26 & -8.64 \\
\hline
\end{tabular}

Table 11. Percent difference between FEM and experimental lower chord stresses mid-Span 3

\begin{tabular}{ccccc}
\hline & Location & S2 & S3 & S4 \\
\hline \multirow{2}{*}{ Lower Chord } & Sensor Number & C8 & C11 & C14 \\
& Field Measurement & & -12.67 \\
\hline
\end{tabular}

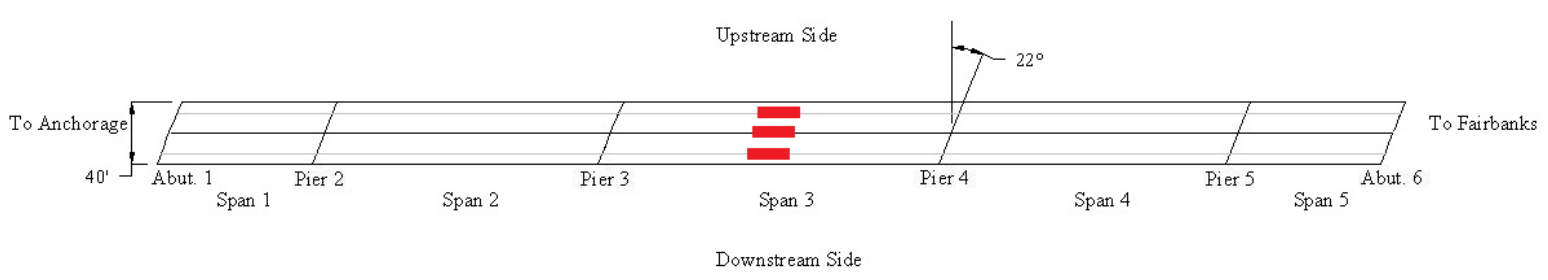

Figure 15. Three trucks positioned on Span 3, southbound

The FEM that resulted from modifications to better predict transverse response was evaluated for both local and global data. Using the improved model, global natural frequencies were calculated and compared with those that were measured with the portable accelerometers. Natural frequencies were calculated in three directions (vertical, longitudinal, transverse) and compared with the measured values (Table 12). The largest error was $8.9 \%$ for the first mode in the longitudinal direction. Based on a comparison between test data and calculated values, it is clear that the modified FEM is sufficiently accurate. 
Table 12. Year 2012 natural rrequency difference; calibrated FEM

\begin{tabular}{cccc}
\hline Mode & Field Measured $(\mathrm{Hz})$ & FEM Results $(\mathrm{Hz})$ & Difference $(\%)$ \\
\hline Longitudinal Mode 1 & 1.500 & 1.367 & 8.9 \\
Longitudinal Mode 2 & 2.190 & 2.044 & 6.7 \\
Vertical Mode 1 & 2.846 & 2.756 & 3.2 \\
Vertical Mode 2 & 3.224 & 3.348 & -3.8 \\
Vertical Mode 3 & 4.586 & 4.249 & 7.3 \\
Transverse Mode 1 & 2.095 & 2.269 & -8.3 \\
Transverse Mode 2 & 2.346 & 2.542 & -8.4 \\
Transverse Mode 3 & 2.782 & 2.788 & -0.2 \\
\hline
\end{tabular}

\subsection{Updated Finite Element Model}

A simple accuracy test was conducted to refine the mesh to ensure that it converged to a reasonable estimation of the response. The simple accuracy test results showed that the original FEM had a mesh size that would provide an acceptable level of accuracy.

Next, we calibrated the FEM against structural response, which was done by modifying elements and structural properties to more accurately describe the as-is bridge structure. The modification process was divided into two stages: one is model updating in the longitudinal direction and another is in the transversal direction. In each stage, the accuracy of the modified FEM was checked against structural response as measured by the sensors at the local level in its direction (the structural health monitoring system) and global level frequency response as measured with 15 portable accelerometers placed on the bridge deck. Finally, to check the multi-direction updated FEM's accuracy was in acceptable limit by using load test data (Figure 16).

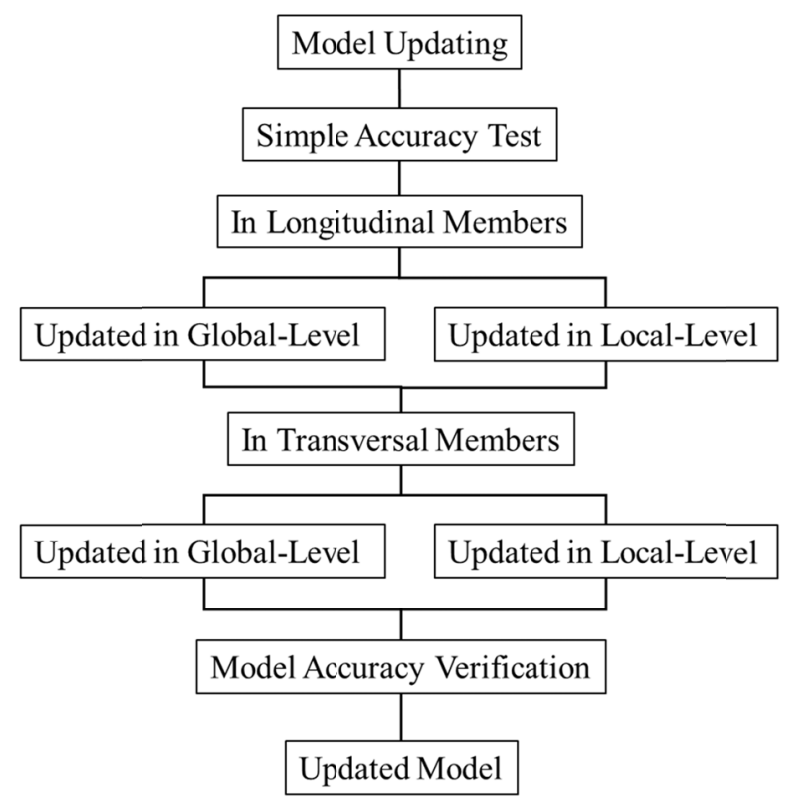

Figure 16. Multi-direction Model Updating Flowchart

Longitudinal members such as the girder flanges, stringer flanges, composite truss lower-chord cross area, and elastic modulus of the concrete deck were selected for study to determine if these items were accurately describing the as-is bridge structure. On September 10, 2012, three ADOT\&PF dump trucks were used to load test the bridge. Static and dynamic strains, tilts, and displacements were measured for seventeen different combinations of truck positions. The measured local response data caused by these different load tests were compared with the FEM results; the differences between experimental and calculated data are the longitudinal 
objective functions. Longitudinal variables were selected and adjusted to match construction drawings so that response was within a reasonable range.

The purpose was to reduce the number of objective functions and variables. In addition to verifying that calculated local strains were sufficiently accurate, we checked calculated global (vertical, longitudinal, transverse) natural frequencies against measured values. This check ensured that element and material property corrections for the model would result in convergence between measured and calculated in global-level.

In the transverse direction, the unconnected roller bearings and cross frames were selected for study. The transverse behavior was studied by evaluating load test response when two trucks were stopped at two critical cross sections. The difference between measured local strain values and calculated were evaluated and compared. The model was reviewed and modified to describe the as-is bridge condition. This process was continued until the model accurately described the behavior and the calculated values correlated well to the experimental values in multi-level.

After model modifications, both local and global values resulted in lower errors between measured and calculated. The longitudinal $\mathrm{J}_{1}$, transversal $\mathrm{J}_{2}$ and multi-direction objective functions $\mathbf{J}$ shows in Figure 17 . Model updating in longitudinal direction have limited influence on transversal member. According to the Figure 17, the longitudinal objective function enhanced $99 \%$ after updated in longitudinal direction, however, transversal objective function only increased $1 \%$. On the other hand, updating in transversal direction can result $97 \%$ changed in transversal objective function, but only enhanced 3\% in longitudinal direction. This results firmly proved that the steel girder bridge model updated in one direction have limited influence on other direction and only updating steel girder bridge in longitudinal member couldn't get accurate bridge finite element model.

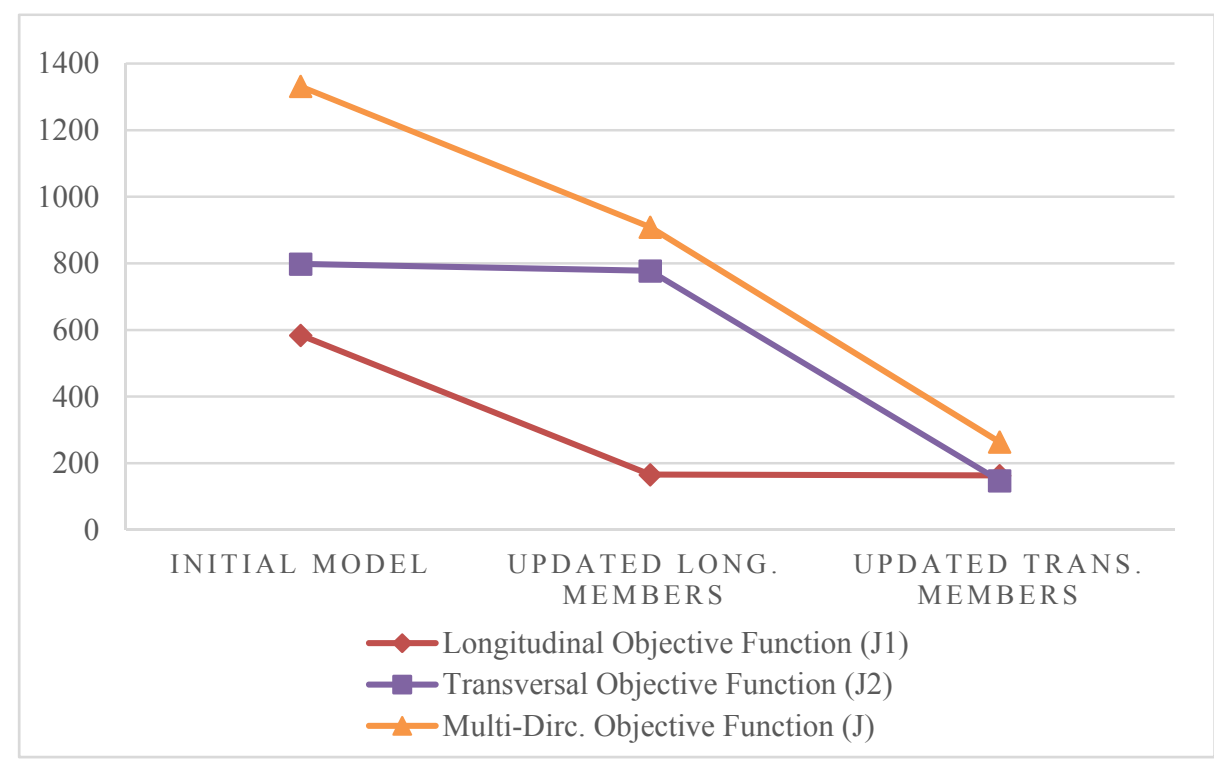

Figure 17. Objective with Model Development

For local values, the largest error decreased from $-512.3 \%$ to $-19.9 \%$. For global values, the largest error decreased from $-10.2 \%$ to $8.9 \%$. The modified or refined (calibrated) FEM now provides calculated values with an accuracy that is within acceptable limits for both local and global values.

\section{Conclusion}

This research established a fiber optic structural health monitoring system for the Chultina River Bridge. The system indicates the real-time local behavior of bridge. Ambient test identified the bridge global response. Combining the local-global test data to update bridge finite element model can eliminate the weakness of only relay on one type of test results to update model. Multi-direction model updating approach separates the model updating into several stage which will help to reduce the number of objective functions and variables and make the function easy to coverage. From the updating results, this study shows only updating longitudinal members, such as girders, stringers and deck have limited enhancement in the overall accuracy of the model. The updating 
uni-direction have every low influence on the accuracy of other directions. The overall accuracy is contributed by both longitudinal members and transversal members. It is necessary for steel girder bridge to be updated in the multi-direction.

\section{Reference}

Bedon, C., \& Morassi, A. (2014). Dynamic Testing a Parameter Identification of a base-isolated bridge. Engineering Structures, 60, 85-99. http://dx.doi.org/10.1016/j.engstruct.2013.12.017

Caglayan, O., Ozakgul, K., \& Tezer, O. (2012). Assessment of Existing Steel Railway Bridges. Journal of Constructional Steel Research, 69, 54-63. http://dx.doi.org/10.1016/j.jcsr.2011.08.001

Dan, D. H., Yang, T., \& Gong, J. X. (2014). Intelligent Platform for Model Updating in a Structural Health Monitoring System. Mathematical Problems in Engineering. http://dx.doi.org/10.1155/2014/628619

Goulet, J. A., Michel, C., \& Smith, I.F.C. (2013). Hybrid probabilities and error-domain structural identification using ambient vibration monitoring. Mechanical Systems and Signal Processing, 37, 199-212. http://dx.doi.org/10.1016/j.ymssp.2012.05.017

HDR, Inc. (2011). Load Rating and Structural Assessment Load Rating Report-Bridge No. 255: Chulitna River Bridge.

Hulsey, J. L., \& Xiao, F. (2013). Structural Health Monitoring and Condition Assessment of Chulitna River Bridge: Mid-Span Loading Report. Alaska Department of Transportation Research, Development, and Technology Transfer, report, Fairbanks, Alaska; 2013.

Jung, D. S., \& Kim, C. Y. (2013). Finite Element Model Updating of a Simply Supported Skewed PSC I-girder Bridge Using Hybrid Genetic Algorithm. KSCE Journal of Civil Engineering, 17(3), 518-529. http://dx.doi.org/10.1007/s12205-013-0599-z

Liu, Y., Li, Y., Wang, D. J., \& Zhang, S. Y. (2014). Model Updating of Complex Structures Using the Combination of Component Mode Synthesis and Kriging Predictor. The Scientific Word Journal.

Perea, R., Marin, R., \& Ruiz, A. (2013). Static-dynamic Multi-scale Structural Damage Identification in a Multi-objective Framework. Journal of Sound and Vibration, 332, 1484-1500. http://dx.doi.org/10.1016/ j.jsv.2012.10.033

Sanayei, M., Phelps, J. E., Sipple, J. D., Bell, E. S., \& Brenner, B. R. (2012). Instrumentation, Nondestructive Testing, and Finite-Element Model Updating for Bridge Evaluation Using Strain Measurements. Journal of Bridge Engineering ASCE. http://dx.doi.org/10.1061/(ASCE)BE.1943-5592.0000228

Schlun, H. Plos, M., \& Gylltoft, K. (2009). Improved Bridge Evaluation through Finite Element Model Updating Using Static and Dynmic Measurements. Engineering Structures, 31, 1477-1485. http://dx.doi.org/10.1016/ j.engstruct.2009.02.011

Xiao, F., Chen, G. S., \& Hulsey, J. L. (2014). Experimental Investigation of a Bridge under Traffic Loadings. Advanced Materials Research Vols., 875-877, 1989-1993. http://dx.doi.org/10.4028/www.scientific.net/ AMR.875-877.1989

\section{Copyrights}

Copyright for this article is retained by the author(s), with first publication rights granted to the journal.

This is an open-access article distributed under the terms and conditions of the Creative Commons Attribution license (http://creativecommons.org/licenses/by/3.0/). 